\title{
ДИНАМИКА ПОКАЗАТЕЛЕЙ СОРЕВНОВАТЕЛЬНОЙ ГОТОВНОСТИ СПОРТСМЕНОВ ВЫСОКОЙ КВАЛИФИКАЦИИ АКАДЕМИЧЕСКОЙ ГРЕБЛИ
}

Попова И.А., Мельник Е.В. (Белорусский государственный университет физической культуры, Минск, Республика Беларусь) popovoi@mail.ru, elizavetamelnik@yandex.ru

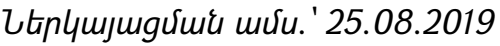

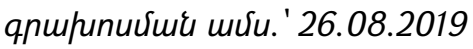

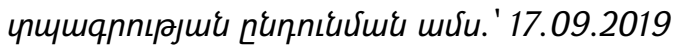

В статье представлены результаты исследования соревновательной готовности спортсменов высокой квалификации циклических видов спорта на примере академической гребли. Установлена динамика показателей энергетического потенциала и уровня стрессового фрона, диагностируемых посредством метода газоразрядной визуализации (ГРВ), уровня тревожности и мотивации в предсоревновательном периоде подготовки. Установленная взаимосвязь психических и функциональных компонентов готовности служит исходной предпосылкой для определения интегрального показателя соревновательной готовности, на основе которого может осуществляться планирование объема и интенсивности нагрузок в циклических видах спорта, прогнозироваться стабильность реализации подготовленности в соревновательном сезоне.

Ключевые слова: академическая гребля, активачия, мотивачия, подготовительный период, соревновательная готовность, тревожность.

Проблемная ситуация в спорте высших достижений заключается в том, что последние годы значительно возросла конкуренция и объем нагрузок, особенно в циклических видах, что отмечается по результатам многочисленных исследований [4]. Для повышения уровня соревновательной готовности спортсменов необходим поиск наиболее информативных показателей, а также их регулярный и оперативный контроль. Это даст возможность индивидуального, точечного подбора средств и методов коррекции неблагоприятных изменений готовности спортсмена.

В циклических видах спорта одним из условий высокой готовности к соревнованиям является соответствующий уровень функциональной и физической готовности. Он возможен при выполнении запланированного объема нагрузки в течение подготовительного периода, где ключевым является высокая работоспособность, переносимость тренировочных нагрузок и адаптация к физическому и психическому напряжению. Процессы адаптации затрагивают весь организм и психическую сферу в том числе, отражаясь на психическом состоянии спортсмена. А.В. Алексеев рекомендовал рассматривать в качестве одного из условия высокой результативности спортивной деятельности оптимальный уровень эмоционального возбуждения. Понимая под уровнем эмоционального возбуждения определенную 
силу волнения, в котором находится человек. Если волнение велико, говорят об очень высоком уровне эмоционального возбуждения, когда наступает успокоение, констатируют, что уровень возбуждения снизился [1, с. 21].

При высоком возбуждении нарушается точность двигательной программы, что не позволяет спортсмену реализовать свой потенциал, а при низком возбуждении низкая фризическая активность и замедленные нервные процессы так же ограничивают реализацию. Это подтверждает и «Гипотеза перевернутого U», согласно которой «с увеличением уровня возбуждения будет повышаться и уровень физической активности-вплоть до оптимального уровня, который характеризуется наивысшими результатами» [7, с. 71]. С ростом спортивных результатов и увеличения объема нагрузки контроль уровня эмоционального возбуждения спортсменов высокой квалификации становится необходимым на всех периодах подготовки и особенно перед соревнованиями.

Значимым для эффективной деятельности является и уровень мотивации. Согласно, первого закона Йеркса-Додсона, возрастание интенсивности мотивации и качество деятельности изменяется соответственно колоколообразной кривой: сначала возрастает, а затем, перейдя через точку высших показателей успешности деятельности, постепенно снижается [8].

Соревновательная готовность является интегративным динамическим компонентом спортивной деятельности, в котором соотношение и уровень отдельных показателей на различных этапах подготовки варьирует. Для прогнозирования успешности выступления спортсменов высокой квалификации на ответственных соревнованиях важна не однократная констатация уровня отдельных показателей, а динамика уровня активации, энергетического потенциала, тревожности и мотивации, соотношение этих показателей во взаимосвязи со специальной физической подготовленностью и стабильностью соревновательных результатов. Данные теоретические предпосылки легли в основу для проведения эмпирического исследования по выявлению информативных показателей соревновательной готовности, их оперативной оценки и своевременной коррекции.

Цель исследования - анализ динамики и взаимосвязи показателей соревновательной готовности спортсменов высокой квалификации в академической гребле на подготовительном периоде подготовки.

Исследование проводилось на базе РЦОП по академической гребле (женская команда) в двух заключительных микроциклах учебно-тренировочного сбора, в предсоревновательном периоде двух сезонов 2014-2015 и 2015-2016 гг. Выборку испытуемых составила женская национальная команда Республики Беларусь по академической гребле и ее резерв - 15 спортсменок, из них МСМК - 6 и МС - 9.

Для контроля функциональных состояний в циклических видах мы выбрали экспресс методы диагностики, которые апробированы и успешно используются специалистами в подготовке спортсменов высокой квалификации. Преимущество 
экспресс методик в быстроте проведения тестирования и получения точной информации, что дает возможность тренеру своевременно корректировать тренировочный процесс, а спортивным психологам подбирать необходимые методы психического восстановления [3].

В исследовании использовались опросники: шкала реактивной тревоги И. Спилбергера, шкала актуального мотивационного состояния В.Ф. Сопова. Для анализа психических состояний спортсменов высокой квалификации академической гребли в подготовительном периоде подготовки мы взяли за основу данные оптимального состояния В.Ф. Сопова для эффективной работы в тренировочном процессе: уровня мотивации 20-22 балла; уровня реактивной тревоги от 8 до 10 баллов [6, с. 69].

Для анализа и контроля функционального состояния спортсменов использовался метод газоразрядной визуализации (ГРВ). В 1995 г. был разработан первый ГРВ прибор и введен термин «метод газоразрядной визуализации - ГРВ» Коротковым К.Г. и группой ученых и разработчиков метода[2]. В многочисленных работах П.В. Бундзена представлена многолетняя исследовательская работа возможностей использования метода ГРВ в спорте. Проведенные исследования свидетельствовали, что параметры ГРВ-грамм, отражающие особенности энергоэмиссионных процессов, обнаруживают статистически достоверную связь с психоэмоциональным состоянием, психофизической готовностью и успешностью соревновательной деятельности высококвалифицированных спортсменов [5]. Метод ГРВ позволил оценить основные 2 параметра, важные для оценки состояния спортсмена - энергетический потенциал (ФЭИ) и уровень стрессового фона (А). Энергетический потенциал - характеризует психофизиологическое состояние спортсмена, вычисляется в процентах от 0 до 100. ФЭИ на уровне $100 \%$ характеризует высокую степень психофизиологической готовности и высокий энергетический резерв. Стрессовый фон (А) - характеризует уровень тревожности, стресса. Уровень стресса измеряется в относительных единицах от 0 до 10, где 10 единиц соответствует максимальному уровню стрессового фона [2].

Оценка специальной функциональной подготовленности проводилась посредством тестирования на гребном тренажере «Concept» - тест 2000 м.

Статистическая обработка результатов проводилась с использованием программы STATISTICA 7, выявлялись основные статистические характеристики, взаимосвязь между показателями определялась на основе корреляционного анализа.

На рисунках 1 и 2 представлены показатели соревновательной готовности спортсменов академической гребли. 


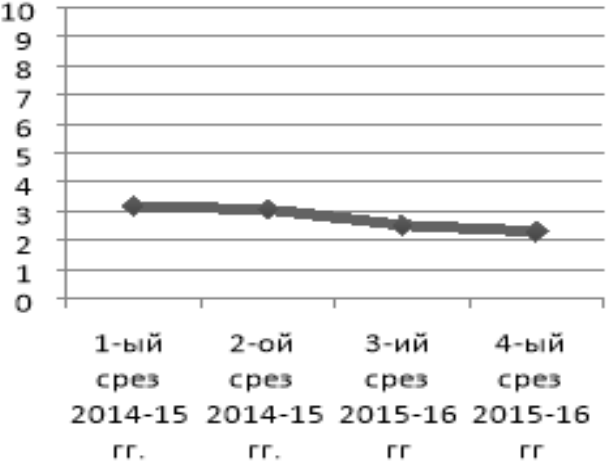

Уровень стрессового фона (А), балл

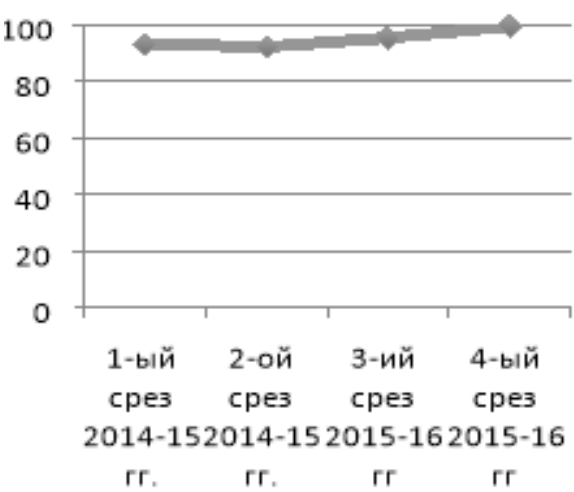

Энергетический потенциал (ФЭИ), \%

Рисунок 1. Показатели методики газоразрядной визуализации.

У спортсменок академической гребли установлен оптимальный уровень стрессового фона, который на протяжении всех двух лет находится в пределах нормы (от 2 до 4 баллов), Его снижение к завершающему предсоревновательному

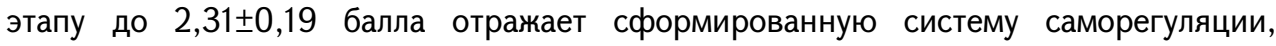
хороший адаптационный потенциал у высококвалифицированных спортсменов, их функциональное состояние. Соревновательные результаты более успешных спортсменов подтверждают значимость учета этого показателя.

Показатель энергетического потенциала поступательно повышается, начиная со второго периода, достигая максимума к завершающему предсоревновательному этапу 99,55 $\pm 0,26 \%$, при р меньше 0,05, что отражает качество психического восстановления после тренировки и высокую активацию всех систем организма спортсменок для достижения наивысших результатов.

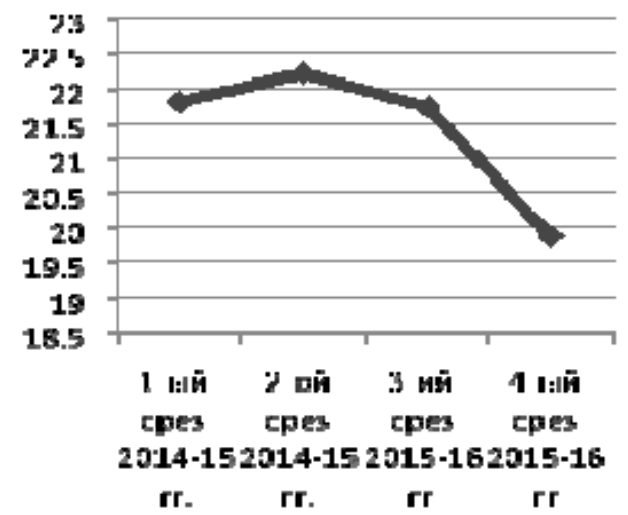

Уровень мотивации, балл

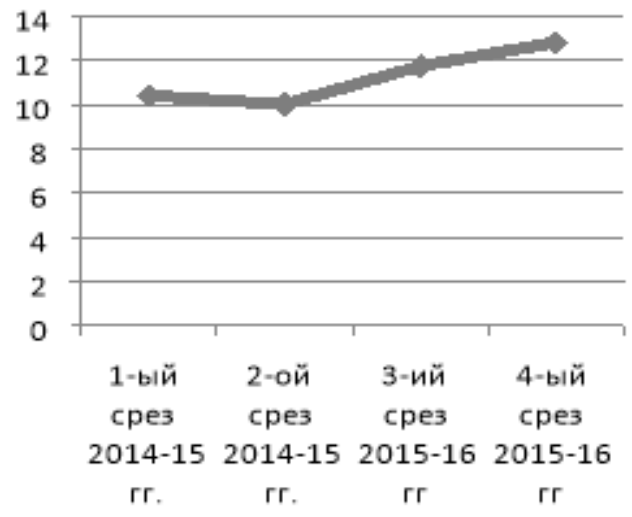

Уровень тревожности, балл

Рисунок 2. Показатели шкалы актуального мотивационного состояния В.Ф. Сопова 
Было установлено, что в целом уровень мотивации у спортсменок являлся оптимальным, что по мнению В.Ф. Сопова отражает оптимальное отношение к тренировочной деятельности [6, с. 65-66]. На первых двух этапах предсоревновательной подготовки отмечено ее нарастание до максимальной величины

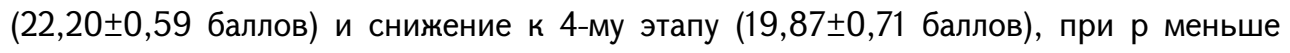
0,05. Повышение уровня мотивации отражает наличие совокупности доминирующих мотивов, побуждающих к активности и снижении внимания на простые действия, что актуально на этом этапе подготовке, на который приходятся наибольшие объемы фризической нагрузки. Снижение мотивации у спортсменов возможно вследствие наличия сомнений в методике тренировки или низкой оценке своих шансов на попадание в состав экипажа. Однако, можно рассмотреть и положительную роль снижения мотивации, как защитного механизма для снижения мешающего чувства ответственности, долженствования. Данные показатели мотивации обуславливают достижение высоких спортивных результатов.

По шкале тревожности для спортсменок академической гребли имеют средний уровень, что является оптимальным для тренировочной деятельности на предсоревновательном этапе подготовки. Отмечена тенденция к нарастанию трево-

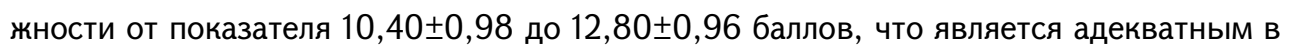
связи с приближением соревнований. Низкий уровень тревожности может свидетельствовать о самоуспокоенности и недостаточной мобилизации усилий в тренировочном процессе. Это предусматривает проведения серии мероприятий специальной психологической подготовки по поддержанию уровня тревожности на оптимальном.

Оценка специальной функциональной подготовленности проводилась 2 раза по завершению подготовительного периода посредством тестирования на гребном тренажере "Concept» - тест 2000 м. Отмечено улучшение результатов от $420,53 \pm 1,58$ до 418,53 1 1,87 секунд, что может быть обусловлено высокой специальной фризической подготовленностью и верное планирование объема и интенсивности нагрузок в подготовительном периоде.

Были установлены значимые корреляционные связи между показателями соревновательной готовности в предсоревновательном периоде двух сезонов 20142015 и 2015-2016 гг. Значимые связи оценки функционального состояния с уровнем стресса $(r=0,56)$, тревожности и мотивации $(r=-0,56)$, стабильности мотивации $(r=0,65)$ на втором сезоне показывают информативность используемых показателей для характеристики уровня соревновательной готовности и прогнозирования высоких спортивных результатов. Для первого сезона значимыми являются связи между энергетическим потенциалом и показателем тревожности ( $r=-$ $0,71)$, мотивацией $(r=0,59)$, мотивацией и тревожностью, а также двумя срезами показателей ФЭИ $(r=0,59)$, мотивации $(0,59)$ и тревожности $(r=0,79)$. 
Проведенное исследование показало значимость регулярного контроля показателей психической и функциональной готовности в течении предсоревновательного периода подготовки, это дает возможность внесения оперативных коррекций в систему подготовки спортсмена, индивидуализировать выбор средств и методов специальной психологической подготовки. Результаты анализа функциональных и мотивационных состояний спортсменок высокой квалификации академической гребли свидетельствуют о стабильном и оптимальном уровне этих показателей, что отражает оптимальное сочетание тренировочной нагрузки и восстановления в предсоревновательном периоде и подтверждается результативность в соревнованиях.

\section{Литература}

1. Алексеев А. В. Преодолей себя! Психическая подготовка в спорте: изд. 5-е, пер. и доп. - Ростов- н/Д: Феникс, 2006, 352 с.

2. Коротков К.Г., Короткова А.К. Инновационные технологии в спорте: исследование психофизиологического состояния спортсменов методом газоразрядной визуализации. - М.: Советский спорт, 2008, 278 с.

3. Попова, И.А. Применение экспресс-методов оценки психофизиологического состояния спортсменов национальных команд в практике спортивного психолога // Материалы Междунар. науч. конф. «Ананьевские чтения 2018: Психология личности: традиции и современность» (Санкт-Петербург, 23-26 окт. 2018 г.); под общ. ред. Н.В. Гришиной, С.Н. Костроминой. Отв. ред. И.Р. Муртазина, М.О. Аванесян. - СПб.: 2018, С. 446-447.

4. Рыбина, И. Л. Биохимические аспекты оценки адаптации организма высококвалифицированных спортсменов циклических видов спорта к напряженным фризическим нагрузкам: автореф. дис. ... д-ра биол. наук: 14.03.11 - М., 2016, 48 с.

5. Бундзен П.В., Загранцев В.В., Колодий О.В., Коротков К.Г., Масанова Ф.М. Новая технология прогнозирования психической готовности спортсменов в олимпийском спорте // Вестник спортивной медицины России. - 1999. - № 3(24). - С. 13.

6. Сопов, В.Ф. Графическая интерпретация результатов экспресс диагностики психических состояний в целях психологической подготовки // Спортивный психолог, 2005, № 3 (6), С. 65-71.

7. Уэйнберг, Р.С., Гоулд Д. Основы психологии спорта и фризической культуры. - Киев: Олимпийская литература, 2001, С. 71.

8. Yerkes R., Dodson J. The relation of strength of stimulus to rapidity of habitformation // j. Comp. Neurol. Psychol. 1908, N 18, p. 459-482. 


\section{DYNAMICS OF INDICATORS OF COMPETITIVE READINESS OF ATHLETES OF HIGH QUALIFICATION OF ACADEMIC ROWING}

Popova I.A., Melnik E.V. (Belarusian State University of Physical Education, Minsk, Belarus)

The article presents the results of a study of the competitive preparedness of highly qualified athletes in cyclic sports using the example of rowing. The dynamics of the indicators of the energy potential and the level of stress background diagnosed by the method of gas discharge visualization (GDV), the level of anxiety and motivation in the pre-competitive training period is established. The established relationship between the mental and functional components of preparedness serves as the initial prerequisite for determining the integral indicator of competitive readiness, on the basis of which planning the volume and intensity of loads in cyclic sports can be carried out, and the stability of the implementation of preparedness in the competitive season can be predicted.

Keywords: rowing, activation, motivation, preparatory period, competitive readiness, anxiety. 